\title{
RELAÇÕES HUMANAS COM BASE EM DINÂMICA DE GRUPO EM UMA INSTITUIÇÃO DE PRESTAÇÃO DE SERVIÇOS
}

André Francisco Pilon*

Desenvolver relações humanas com base em dinâmica de grupo significa criar um espaço psicossocial alternativo, em que desconfianças, temores e conflitos possam ser aceitos e trabalhados, mediante experiências reconstrutivas, em termos de tarefas e processos que minimizem as ameaças ao "ego" e desenvolvam formas de interação compativeis com uma ampliação quantitativa e qualitativa de cognições, afetos e condutas.

Essa reconstrução implica o desenvolvimento de um clima de confiança mútua, em que todas as cartas possam ser colocadas na mesa, onde as fórmulas de cortesia ou de ataque-e-defesa possam ser substituídas pela genuína consideração pelo outro, pelo compartilhamento de pensamentos, sentimentos e açōes, pela adesão a uma tarefa comum gerada pelo próprio grupo em direção ao seu auto-conhecimento.

Nesse sentido, os papéis desenvolvidos no grupo propiciarão a atualização das diferenças individuais e não receitas de condutas normativas, o desenvolvimento de conceitos como frutos da interação, a aprendizagem de novas maneiras de interagir, desenvolvendo as habilidades e talentos, à maneira dos diferentes músicos que compõem uma orquestra. Sanções, persuasão, manipulação cedem lugar a uma relação de integração, permitindo encontrar soluções através das quais as partes obtêm seus objetivos sem que nenhuma seja obrigada a sacrificar sua essência (Follet citada por Wahrlich $\left.^{13}, 1969\right)$. Significa trabalhar o conceito de poder não no sentido weberiano, mas de Hannah Arendt (cf. Habermas', 1980).

Discorrer sobre a teoria que informa o desenvolvimento de relações humanas com base em dinâmica de grupo significaria recapitular a vasta literatura gerada a partir de Moreno $^{11}$ (1953) e Lewin ${ }^{5}$ (1978), enriquecida pela contribuição paralela de linha fenomenológica e existencial e revisada pela análise institucional e social (estudo das condições de existência das condutas).

Significaria ainda incorporar os resultados de estudos e pesquisas envolvendo diferentes áreas, como a psicanálise (relaçōes objetais), a psicologia social (atitudes e condutas como expressão da interação), a administração (análise institucional), a sociologia e a antropologia (relações de produção e relações interpes. soais), incluindo aquelas que pretendem entender o microcosmos da dinâmica dos grupos em função de todo um perfil de uma cultura ou "civilização".

Dinâmica de grupo como parte dos estudos que procuram localizar no espaço e no tempo diferentes variáveis ao invés de guiar-se por teorias gerais de mudança social, parece justificada não apenas como intervenção pontual, mas também como forma de operacionalizar mudanças que de outra maneira dependeriam de utópicas alterações "globais", cujos parâmetros oscilam ao sabor de circunstâncias específicas (cf. Cardoso ${ }^{3}, 1986$ ).

Tocando as linhas-mestras de um vasto universo conceitual, o presente trabalho descreve um projeto desenvolvido numa instituição de prestação de serviços, que reuniu diferentes contribuiçōes ao nível teórico, resultando numa síntese pessoal, com raízes na experiência própria de seu autor, mas também inspirada em trabalhos de aplicação como os de Bradford e col. ${ }^{2}$ (1966), Maccio ${ }^{8}$ (1967), Luft $^{6}$ (1970), Mailhiot' (1970), Meigniez ${ }^{10}$ (1970).

O projeto foi desenvolvido na Fundação Legião Brasileira de Assistência (LBA), agência de desenvolvimento social vinculada ao Sistema Nacional de Previdência e Assistência (Ministério da Previdência e Assistência Social), cuja clientela é constituída pela população carente não previdenciária e pelos beneficiários do Instituto Nacional de Previdência Social (INPS), Fundo de Assistência ao Trabalhador Rural (FUNRURAL) e Instituto de Previdência e Assistência dos Servidores do Estado (IPASE) na área da assistência social.

A LBA, além de programas de complementação alimentar e de promoção nutricional, desenvolve os projetos "Casulo" (creches), "Elo" (lazer cultural para menores de 7 a 18 anos), e todo um leque de atividades dirigidas à família e à comunidade, abrangendo saúde, educação, transporte, habitação, vestuário, lazer, cidadania (registro civil).

\footnotetext{
* Departamento de Prática de Saúde Pública da Faculdade de Saúde Pública da Universidade de São Paulo - Av. Dr. Arnaldo, 715 - 01255 - São Paulo, SP - Brasil.
} 
Outros programas são dirigidos à assistência aos excepcionais e aos idosos, à educação para o trabalho (diferentes artes e ofícios) e ao incentivo à micro-empresa (a meta é criar, anualmente, 2 mil micro-empresas, beneficiando 100 mil pessoas). Todos os projetos são apoiados pelo programa nacional de voluntariado (PRONAV/LBA).

Dentro deste contexto de encargos, envolvendo ampla frente de trabalho, o aperfeiçoamento dos servidores técnicos e administrativos visaria não apenas o conteúdo de suas tarefas, mas também os processos empregados, incluindo as habilidades necessárias ao trabalho de equipe que aproveitasse e multiplicasse os talentos individuais em projetos compartilhados por todos.

\section{DESCRIÇÃO DO CURSO DE RELAÇÕES} HUMANAS E DINÂMICA DE GRUPO

$\mathrm{Na}$ ocasião em que desenvolvemos o "Curso de Relações Humanas com Base em Dinâmica de Grupo", os servidores da Superintendência Regional do Espírito Santo, da LBA, já tinham recentemente passado por uma experiência de "relacionamento interpessoal", compartilhada por 50 funcionários, o que teria levado a entidade a ampliar esse tipo de trabalho, a fim de abranger os demais servidores. Para o novo curso elaboramos proposta com os seguintes objetivos:

1. Desenvolver habilidades para trabalho em equipe, integrando teoria e prática de Dinâmica de Grupo.

2. Aumentar a sensibilidade dos participantes em relação às próprias ações e como essas afetam os demais.

3. Aumentar a sensibilidade em relação às ações dos demais e como essas afetam a si próprio.

4. Aumentar a habilidade como facilitadores de grupos de discussão, em termos de tarefa e processo.

5. Possibilitar aos participantes um autoconhecimento em termos de crescimento e desenvolvimento psicossocial.

O curso foi realizado na sede da entidade, em Vitória, ES, no período de 5 a 16 de janeiro de 1987, abrangendo 32 servidores, subdivididos em grupos matutino e vespertino, cada qual com sessões de 3 horas de duração, totalizando 30 horas respectivamente. Servidores técnicos e administrativos compuseram ambos os grupos, além de alguns estagiários.
As experiências em dinâmica de grupo abrangeram, ao longo das sessōes, diferentes situaçōes, visando sensibilização, "insight" (no conceito da "Gestalt"), reflexão, "feedback" (no conceito da teoria da comunicação), domínio de técnicas apropriadas ao trabalho de equipe e de noções fundamentais que informam, do ponto-de-vista teórico, situações vivenciadas no grupo (nível cognitivo, afetivo e operativo).

A análise dos diferentes momentos no desenvolvimento das sessões foi efetuada mediante os próprios processos utilizados na dinâmica, que abrangeu grupos de verbalização e ressonância (Bales $\left.{ }^{1}, 1950\right)$ e outros instrumentos de promoção-avaliação do crescimento do grupo: aspectos referentes à qualidade da comunicação, clima, liderança e compartilhamento de objetivos e papéis (em termos de tarefas e processos).

Além das experiências vivenciadas, textos destinados a propiciar maior reflexão em relação às experiências de dinâmica de grupo foram distribuídos ao longo das sessōes, após um breve comentário e leitura de seus aspectos-chave (Pilon $\left.{ }^{12}, 1971\right)$.

\section{EXPERIENCIAS DE DINÂMICA DE GRUPO}

Descrevemos, a seguir, com pormenores, experiências que não constam da literatura, produzidas com base em nosso trabalho pessoal e desenvolvidas durante o curso.

\section{Apresentação e Presente Simbólico}

Cada participante retira de uma caixa (de sapatos) uma papeleta em branco e nela escreve, com pincel atômico, o nome pelo qual deseja ser conhecido no grupo, repetindo-o em voz alta e respondendo às seguintes questões: "Quem sou? Donde venho? Para onde vou?". Em seguida, a caixa é passada novamente e cada um retirará, sem olhar, uma papeleta com nome, tentando identificar o companheiro e reproduzir para o grupo, com a ajuda deste, o que o colega inicialmente disse sobre si mesmo. Feito isso, a caixa circulará novamente com as papeletas e cada um sorteará um colega para entregar-lhe, com a caixa, um presente simbólico, facultando-se ao presenteado manifestar-se sobre o presente recebido.

\section{Auto-revelação Mediante Uso de Objeto Intermediário}

Dezesseis caixas (de sapato), de diferentes tamanhos, ilustradas interna e externamente 
(inclusive tampas), com gravuras recortadas de revistas afixadas e versando sobre diferentes situações de vida, são pasadas entre os membros do grupo, para conhecimento e, na passagem subsequiente, para escolha e retenção da caixa e da tampa que, por qualquer motivo, tenham despertado o interese de cada um (uma caixa "em branco", sem ilustraçōes, também compõe o conjunto). Cada qual poderá compartilhar com o grupo o significado das escolhas respectivas. As caixas não escolhidas são dispostas no centro do círculo e os participantes poderão indicar suas rejeições, partilhando seus sentimentos como o fizeram em relação às preferências (Fig.).

\section{Associação de Cores e Situações de Vivência}

Os participantes são convidados a escrever numa papeleta o nome de uma cor com a qual associam, num primeiro momento, a própria situação de trabalho e, num momento posterior, a situaçāo vivenciada no grupo. São apresentadas as 7 cores do arco-íris e ainda o branco, o cinza e o preto em um quadro, possibilitando 10 opções diferentes. Após cada qual registrar a cor escolhida, os membros do grupo são convidados a compartilhar com os companheiros os motivos que os teriam levado às escolhas, podendo chegar a uma tabulação de freqüências (não essencial, uma vez que o significado dos comportamentos de seleção de uma mesma cor pode variar no grupo).

\section{Análise da Interação numa Situação Projetiva}

Uma sinopse, adaptação do poema de Rubén Dario, "Os motivos do lobo" (Anexo), é distribuída aos participantes, a fim de que, individualmente, acrescentem uma seqüência à estória relatada e, depois, compartilhem com os demais como cada qual prosseguiria com a estória. $\mathrm{Na}$ discussão das sequiências observam-se convergências e divergências face a um desenlace. São analisadas as figuras de São Francisco, da população e do lobo, procurando desvendar seu aspecto simbólico na estória. A situação vivenciada "dentro" e "fora" do grupo em relação aos objetos "bons" e "maus" introjetados e/ou extrojetados, passa, mediante esse processo, por uma melhor inteligência, após catarse em grupo dos aspectos persecutórios. A experiência acima pode ser precedida pelo relato da estória numa cadeia de comunicação para verificar as situaçōes de distorção da mensagem e, de alguma forma, despertar interesse pela atividade subseqüente de dar sequiência à sinopse do poema.

\section{Perfil do Grupo Face a Valores e Necessidades Básicas}

Inicialmente os membros recebem uma folha de papel, na qual deverão colocar, sem se identificar, o que consideram mais importante para se sentirem satisfeitos com a vida e desfrutar de uma sensação geral de bem-estar, podendo numerar até 5 itens por ordem de importância. As percepções dos membros poderão ser compartilhadas em grupo mediante tabulação geral de frequiências, mas, ao contrário do processo de Delbecq e Van de Ven ${ }^{4}$ (1971), as prioridades de trabalho não repousam sobre os itens que recebem maior pontuação (somatórias das frequiências ponderadas), pois os valores e necessidades do grupo como um todo devem ser considerados e integrados. A tabulação é, assim, apenas uma forma de explicitar o que transparecia no grupo e de estimular os mecanismos de "feedback" (não se reforçam subgrupos hegemônicos).

Por já constarem nas referências bibliográficas, não são descritas outras experiências como os exercícios de cooperação (construção de figuras quadradas) ou de auto-revelação e "feedback" (janela de Jo-Harry) —, além de outros aspectos que implicariam uma descrição passo-a-passo ou sequiencial do processo, não pertinente aos propósitos desta comunicação de mero registro do evento.

Mencionamos, contudo, a avaliação promovida a posteriori, a nível administrativo, pela entidade interessada, para os efeitos de seu programa de desenvolvimento de pessoal e cujos resultados são apresentados na Tabela (foram distribuídos questionários aos participantes, com questōes sobre a parte teórico-prática do curso, a adaptação às necessidades dos servidores, o nível de participação pessoal, as condições do local físico e as perspectivas de melhoria no relacionamento humano).

$\mathrm{Na}$ análise qualitativa (comentários, críticas e sugestōes), figuram expressões de satisfação pessoal pelo evento, entremeadas de sugestões, como a extensão do curso às chefias, sua repetição para os demais servidores, etc. $\mathrm{Na}$ expressão utilizada pelo superintendente estadual da LBA, em manifestação a parte, "os resultados foram muito positivos", devendo ser analisados em reunião de supervisores e discutidos em função da continuidade dos trabalhos. 


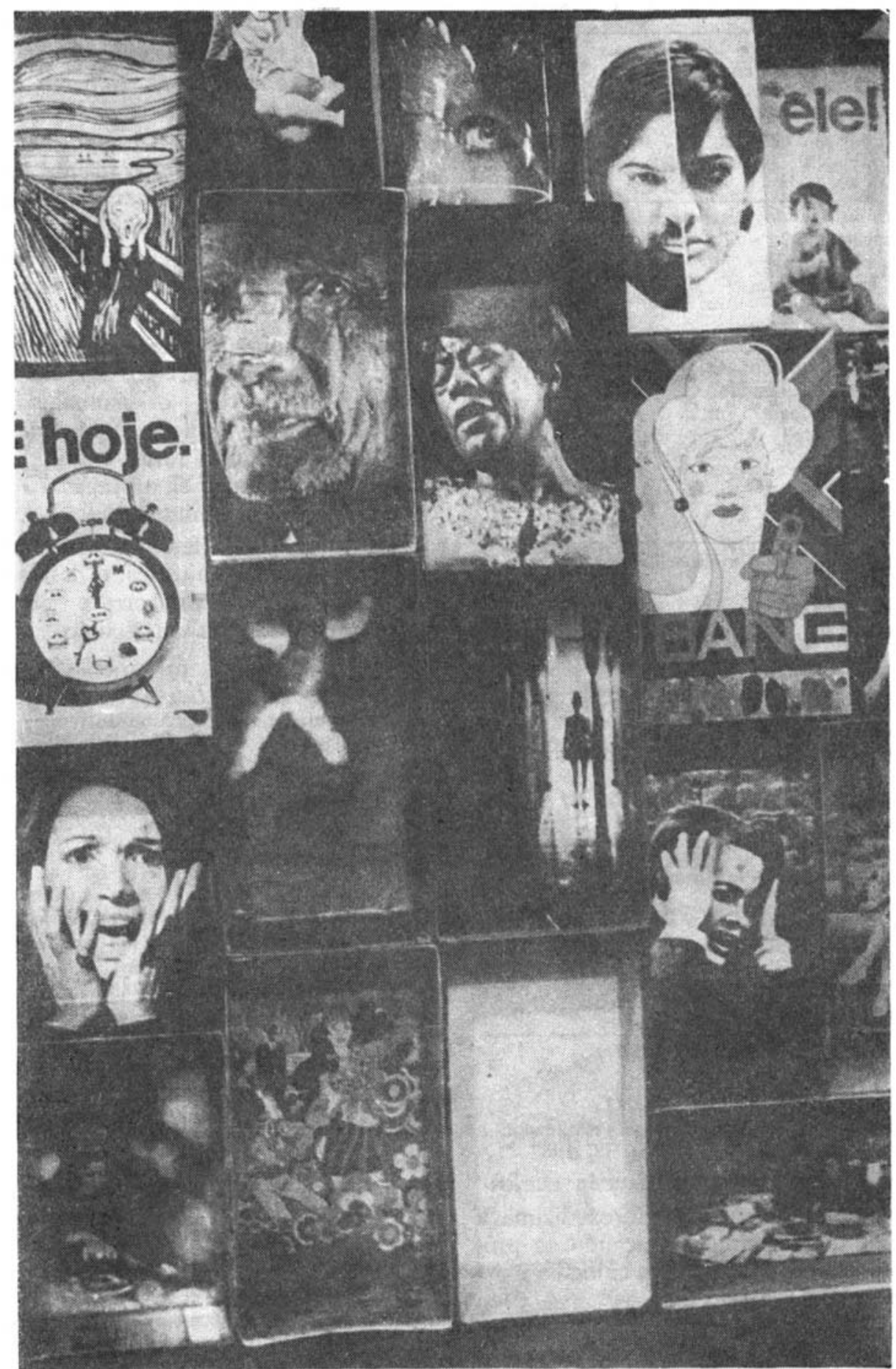

Fig. Caixas (de sapato) ilustradas, utilizadas como "objeto intermediário" para facilitar a expressão de diferentes aspectos do projeto de vida individual e do projeto de vida coletivo. Seu caráter quase lúdico permite o desvelamento a nível de valores, crenças e afetos, incluindo as situaçōes de conflito intrapsíquico, trabalhadas em grupos terapêuticos. 
TABELA

Avaliação do curso segundo critérios da entidade (Fundação Legiăo Brasileira de Assistência)

1. A parte teórica do curso atendeu suas expectativas?

- sim, plenamente

- sim, parcialmente

- não atendeu Total

$21 \quad 75,0$

$07 \quad 25,0$

$00 \quad 0,0$

$28 \quad 100,0$

2. A parte prática do curso atendeu suas expectativas?

- sim, plenamente

- sim, parcialmente

- não atendeu Total

28100,0

3. O curso foi adaptado às

necessidades dos servidores

da Superintendência?

\begin{tabular}{lrr} 
- perfeitamente & 18 & 64,3 \\
- em parte & 09 & 32,1 \\
- muito pouco & 01 & 3,6 \\
- não & 00 & 0,0 \\
Total & 28 & 100,0 \\
\hline
\end{tabular}

4. Você acha que sua participação

no treinamento foi:

- muito grande

- regular

- deficiente Total

1450,0

1450,0

$00 \quad 0,0$

$28 \quad 100,0$

5. O local onde foi desenvolvido

o curso foi:

- ótimo

- bom

- inadequado Total

$28 \quad 100,0$

6. Você acha que o curso contribuirá

para melhorar o relacionamento entre os servidores?

- contribuirá muito

- contribuirá pouco

— nāo contribuirá

- em branco Total

28100,0

Responderam o questionário: 28 pessoas.

\section{A NEXO}

Texto utilizado no Curso de Relações Humanas e Dinâmica de Grupo - Vitória, ES, 1987

(Sinopse segundo o poema de Rubén Dario)*

Em Agubio, Itália, um lobo feroz dizimava as ovelhas e outros animais, atacando os proprios moradores da aldeia e tornando sua existência um verdadeiro flagelo.

Desesperados, recorreram a São Francisco, que se dispôs a tratar com o lobo.

Encontrando-se com ele, admoestou-o docemente, convencendo-o de que poderia obter até seu próprio alimento com a colaboração da população.
E assim passou o animal a conviver pacificamente com as pessoas, recebendo delas bocados de carne e até lambendo-lhes as mãos.

Contudo, chegou um momento em que São Francisco teve que viajar. A partir daí, a população passou a hostilizar o lobo, dando-lhe pauladas e negando-lhe comida.

O lobo voltou então novamente à vida selvagem e retomou o seu comportamento anterior, aterrorizando a população.

Retornando São Francisco, disseram-lhe que a fera não correspondera às atenções das pessoas e que voltara a atacá-las.

Perplexo, procurou São Francisco novamente o lobo. "Não se aproxime muito, irmão Francisco", advertiu o animal, rosnando: "Agüentei demais aquela gente, que me maltratou sem qualquer razão e cujo comportamento, mesmo entre si, ultrapassa, de longe, o que chamam de minha ferocidade".

E a seguir o lobo testemunhou sobre as desavenças, o ódio, a injustiça, o desrespeito mútuo entre homens e mulheres e sobre todo o pecado que observou em Agubio.

\section{REFERENCIAS BIBLIOGRÁFICAS}

1. BALES, R. F. Interaction process analysis. Cambridge, Mass., Addison-Wesley, 1950.

2. BRADFORD, L. P. et al. Dinámica del grupo de discussión. Buenos Aires, Paidós, 1966.

3. CARDOSO, F. H. Problemas de mudança social, outra vez? Novos Est. CEBRAP, (16): 54-61, 1986.

4. DELBECQ, A. L. \& VAN DE VEN, A. H. A group process model for problem identification and program planning. J. appl. Behav. Sci., 7:466-92, 1971.

5. LEWIN, K. Problemas de dinâmica de grupo. São Paulo, Cultrix, 1978.

6. LUFT, J. Introdução à dinâmica de grupo. Lisboa, Moraes Eds., 1970.

7. HABERMAS, J. Sociologia. São Paulo, Ãtica, 1980.

8. MACCIO, C. Animação de grupos. Lisboa, Moraes Eds., 1967.

9. MAIILHIOT, G. B. Dinâmica e gênese dos grupos. São Paulo, Duas Cidades, 1970.

10. MEIGNIEZ, R. $A$ análise dos grupos. São Paulo, Vozes/Ed. USP, 1970.

11. MORENO, J. L. Who shall survive? New York, Beacon House, 1953.

12. PILON, A. F. Técnica de reunião. São Paulo, Faculdade de Saúde Pública da USP, s.d. [Mimeografado].**

13. WAHRLICH, B. M. S. Uma analise das teorias da organização. Rio de Janeiro, Fundação Ge. túlio Vargas, 1969.

Recebido para publicação em 5/3/1987

A provado para publicação em 13/5/1987

* Dario, Rúben. Obras completas. Buenos Aires, Ediciones Anaconda, 1949, p. 249.

** Disponível com o autor do trabalho. Departamento de Prática de Saúde Pública da Faculdade de Saúde Pública da USP. 